\title{
Associate Editor Dénes Molnár
}

We would like to introduce our new associate editor.

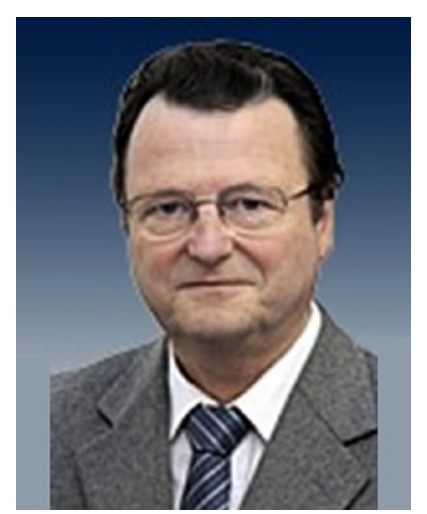

Dénes Molnár, MD, PhD, DSc

Department of Paediatrics, Medical Faculty, University of Pécs, Pécs, Hungary
Dénes Molnár (MD, PhD, DSc) is professor in pediatrics, nutrition, and metabolism at the Department of Paediatrics University of Pécs. He was the chairman of the Department of Paediatrics University of Pécs from 2007 to 2015 . He served as the president for one term, as the scientific advisor of the European Childhood Obesity Group (ECOG) for 2 terms, and as the vice-president of the Hungarian Association for the Study of Obesity. He was the president of the Hungarian Paediatric Association during the period 2012-2015. He is the member of the editorial board of Obesity Facts and Nutrition, Metabolism and Cardiovascular Diseases, Journal of Pediatric Biochemistry and The Scientific World Journal in addition to some other national journals. He has participated in 9 international research programs and won 11 national research grants. He is a PhD program leader in the topic of Nutritional research in children and infants. He specializes in the following fields of medicine: metabolic disorders, eating disorders, prevention of adult diseases in childhood. He has published 350 original articles in peer-reviewed journals and 18 book chapters (cumulative IF: 950.47; number of citations 7,000, Hirsch index: 37 ). 